\title{
The prognostic and predictive value of the Iymphocyte to monocyte ratio in luminal-type breast cancer patients treated with CEF chemotherapy
}

\author{
Hongfei Ji, ${ }^{1,3, *}$, Qijia Xuan ${ }^{2, *}$, Caichuan Yan ${ }^{1,3}$, Tao Liu' ${ }^{2}$, Abiyasi Nanding ${ }^{4}$, Qingyuan \\ Zhang ${ }^{1,2,3}$ \\ ${ }^{1}$ Department of Cancer Molecular and Biology, Cancer Institute, Harbin Medical University, Harbin, China \\ ${ }^{2}$ Department of Medical Oncology, Tumor Hospital of Harbin Medical University, Harbin, China \\ ${ }^{3}$ Department of Cancer Molecular and Biology, Heilongjiang Academy of Medical Sciences, Harbin, China \\ ${ }^{4}$ Department of Pathology, Tumor Hospital of Harbin Medical University, Harbin, China \\ *These authors have contributed equally to this work \\ Correspondence to: Qingyuan Zhang, e-mail: zqyxsci@126.com \\ Keywords: breast cancer, lymphocyte-to-monocyte ratio, 5-fluorouracil, prognostic factor \\ Received: December 03, $2015 \quad$ Accepted: April 11, $2016 \quad$ Published: April 26, 2016
}

\section{ABSTRACT}

Several reports have suggested that peripheral blood-based parameters are associated with host immunity response, which is an essential component of the pathogenesis and progression of cancer. The purpose of the present study was to identify the prognostic significance of various peripheral blood-based biomarkers and to determine the optimal cut-off value suitable for luminal breast cancer patients. We found that lymphocyte-to-monocyte ratio (LMR) was significant prognostic predictors. And the patients with a CEF regimen and LMR ratio $\geq \mathbf{5 . 2}$ gained a good prognosis. This study suggested that the LMR could be regarded as an independent prognostic factor in luminal breast cancer patients. The elevated LMR level also had enhanced 5 -fluorouracil sensitivity in luminal breast cancer patients.

\section{INTRODUCTION}

Breast cancer is a complex and heterogeneous disease, and is categorized into three major subtypes based on gene expression profiles: luminal, basal like, and human epidermal growth factor 2 (HER2) enriched, which exhibit distinct clinical features, responses to specific chemotherapy, and prognosis [1-3]. Despite improvements in treatment, the morbidity and mortality rates in luminal breast cancer remain high [4-5]. Recent breakthroughs in cancer immunology substantiated that the host immune system correlates with cancer development and progression, and immunomodulating therapy has emerged as an effective novel therapeutic strategy [6-9]. Furthermore, the host immune system should be taken into account even during conventional chemotherapy treatment, as it has been found to influence the clinical response to chemotherapy.

Recent reports suggested that the peripheral bloodbased parameters, such as absolute monocyte count (AMC), absolute lymphocyte count (ALC), neutrophilto-lymphocyte ratio (NLR), lymphocyte-to-monocyte ratio (LMR), and platelet-lymphocyte ratio (PLR), are associated with host immunity response [10-14]. Moreover, there is a reliable correlation between the above parameters and increased survival time in a wide range of malignancies [15-19].

To the best of our knowledge, there are no comprehensive data available evaluating a set of peripheral blood-based biomarkers in luminal breast cancers. The purpose of the present study was to identify the prognostic significance of various peripheral blood-based biomarkers, and to determine the optimal cut-off value suitable for luminal breast cancer patients. 


\section{RESULTS}

\section{Patient and tumor characteristics}

Data from two hundred and fifty-nine patients were collected for the analysis. The characteristics of the enrolled patients are generalized in Table 1. The patient median age was 48 years (range, 25-76 years). Over half of all patients $(56.4 \%)$ were premenopausal and $29.3 \%$ had no lymphatic metastasis. The median tumor size was $4 \mathrm{~cm}$. Twenty-five were histological grade I, 220 were histological grade II, and 14 were histological grade III. Two hundred and six (79.5\%) were ER positive, and 222 (85.7\%) were PR positive. Of the 259 cases, 216 (83.4\%) were HER2 IHC level 0/1+, $38(14.7 \%)$ were $2+$, and 5 $(1.9 \%)$ were $3+.31 .3 \%$ of breast tumors were luminal-A breast cancer. Of these, 128 breast cancers were $\geq 20 \%$ (49.4\%) Ki-67 positive and 72 patients were $\mathrm{P} 53$ positive $(27.8 \%)$.

\section{Cutoff values for the LMR in luminal breast cancer patients}

Receiver operating characteristics (ROC) curves and area under the curve (AUC) were used to determine the optimal cutoff points for the LMR, NLR, PLR, AMC, and ALC, based on their utility as markers for the clinical outcome of relapse, cancer-related death. Regarding the LMR in luminal breast cancer patients, 5.2 was identified as the optimal cutoff point for distinguishing good prognosis patients from poor prognosis patients $(P=0.006)$ (Figure 1). There was no statistically significance in NLR, PLR, AMC, or ALC by ROC analyses (Figure 1).

The mean counts of lymphocytes were $1.76 \times 10^{9} / \mathrm{L}$ (range, $0.4-5.3 \times 10^{9} / \mathrm{L}$ ) and the mean counts of monocytes were $0.41 \times 10^{9} / \mathrm{L}$ (range, $0.1-2.2 \times 10^{9} / \mathrm{L}$ ) (Table 1 ). The mean LMR level was 5.4 (range, 0.3-27.7) (Table 1). All patients were also divided into either low- $(<5.2)$ or high$(\geq 5.2)$ LMR groups. The mean lymphocyte count in the low-LMR and the high-LMR groups were $1.59 \times 10^{9}$ and $1.98 \times 10^{9}$, respectively $(P<0.001)$ (Table 1$)$. The mean monocyte counts in the low- and high-LMR groups were $0.51 \times 10^{9}$ and $0.28 \times 10^{9}$, respectively $(P<0.001)$ (Table 1$)$.

\section{Survival in terms of LMR status and chemotherapy}

The optimal LMR cutoff point distinguished patients with a good prognosis. Kaplan-Meier survival curves analysis showed that the disease-free survival (DFS) in luminal breast cancer patients with a LMR $\geq 5.2$ was significantly longer than those with a LMR $<5.2(P=0.001)$ (Figure 2).

Patients with luminal breast cancer were also divided into two groups according to the chemotherapy regimens (CEF or TAC) after surgery. In luminal breast cancer patients with a LMR $\geq 5.2$, Kaplan-Meier survival curves demonstrated that the DFS in patients with the CEF regimen was significantly longer than in those with the TAC regimen $(P<0.05)$ (Figure 3$)$.

\section{Univariate and multivariate analyses of clinicopathologic characteristics for DFS in luminal breast cancer}

Results of univariate and multivariate analysis to identify prognostic factors for DFS in luminal breast cancer patients are shown in Table 2. When the correlation between clinicopathological variables and DFS were analyzed by univariate analysis, LMR [hazard ratio (HR) $=0.560 ; 95 \%$ CI, $0.395-0.793 ; P=0.001]$, lymph node status $(\mathrm{HR}=1.748 ; 95 \% \mathrm{CI}, 1.167-2.620 ; P=0.007)$, and chemotherapy $(\mathrm{HR}=1.676$; 95\% CI, 1.143-2.458; $P=0.008)$ were significantly related to a higher risk of recurrence. Similarly, LMR and chemotherapy also showed a significant association with DFS by multivariate analysis.

\section{Expression of FAS in cell lines MCF-7 and T47D treated 5-fluorouracil and paclitaxel}

The MCF-7 and T47D cells are both luminal breast cancer cells. FAS expressions in 5-fluorouracil (5-FU) treated MCF-7 and T47D cell lines were higher than that in paclitaxel treated cell lines $(P<0.01$ and $P<0.01$, respectively), as shown in Figure 4.

\section{DISCUSSION}

In the present study, we performed a cohort study in 259 luminal breast cancer patients to evaluate the prognostic value of several peripheral blood-based biomarkers. We found that only the LMR was significantly associated with survival time in luminal breast cancer patients. Although there is limited evidence elucidating the mechanisms underlying the prognostic significance of the LMR, the lymphocytes and monocytes involved in host immune response may be a possible explanation [17, 23-26].

Lymphocytes and macrophages are the fundamental components of the tumor microenvironment [27-30]. For example, lymphocytes are pivotal mediators responsible for eliciting a positive immune response [28-32]. On the contrary, monocytes are known to infiltrate tumors and differentiate into tumor-associated macrophages, which are involved in tumor proliferation, invasion, metastasis, neovascularization, and recurrence [27-28, 33-34]. The advantage of the LMR index is that it is able to combine the information from lymphocytes and monocytes, and more comprehensively indicate the status of the host immune response. 
Table 1: Characteristics of luminal breast cancer according to the lymphocyte-to-monocyte ratio

\begin{tabular}{lcccc}
\hline Characteristic & Overall(\%) & LMR $<\mathbf{5 . 2}$ & LMR $\geq \mathbf{5 . 2}$ & P-value \\
\hline Age & & & & \\
$\quad \mathbf{5 0}$ & $148(57.1)$ & 86 & 62 & $0.450^{\mathrm{a}}$ \\
$\quad \mathbf{5 0}$ & $111(42.9)$ & 59 & 52 & \\
Menopause status & & & & \\
$\quad$ No & $146(56.4)$ & 84 & 62 & \\
$\quad$ Yes & $113(43.6)$ & 61 & 52 & \\
Tumor size(cm) & & & & $0.294^{\mathrm{a}}$ \\
$\quad<\mathbf{2}$ & $56(21.6)$ & 35 & 21 & \\
$\geq \mathbf{2}$ & $203(78.4)$ & 110 & 93 &
\end{tabular}

Nodal status

$\begin{array}{llccc}\text { No } & 76(29.3) & 37 & 39 & 0.133^{\mathrm{a}} \\ \mathbf{N}+ & 183(70.7) & 108 & 75\end{array}$

Histological grade

$\begin{array}{lccr}\text { I } & 25(9.7) & 16 & 9 \\ \text { II } & 220(84.9) & 124 & 96 \\ \text { III } & 14(5.4) & 5 & 9\end{array}$

ER status

$\begin{array}{cccc}\text { ER+ } & 206(79.5) & 118 & 88 \\ \text { ER- } & 53(20.5) & 27 & 26\end{array}$

\section{PR status}

$\begin{array}{cccc}\text { PR+ } & 222(85.7) & 120 & 102 \\ \text { PR- } & 37(14.3) & 25 & 12\end{array}$

HER2 status by IHC

$\begin{array}{cccc}\mathbf{0} / \mathbf{1}+ & 216(83.4) & 126 & 90 \\ \mathbf{2}+ & 38(14.7) & 16 & 22 \\ \mathbf{3 +} & 5(1.9) & 3 & 2\end{array}$

Ki 67status

$\begin{array}{ll}<\mathbf{2 0 \%} & 131(50.6) \\ \geq \mathbf{2 0 \%} & 128(49.4) \\ \mathbf{5 3} \text { status } & \end{array}$

96

9

\section{Positive}

$72(27.8)$

42

88

$0.440^{\mathrm{a}}$

Negative

$187(72.2)$

103

30

$0.677^{\mathrm{a}}$

Luminal subtype

Luminal A

81 (31.3)

50

31

$0.226^{\mathrm{a}}$

Luminal B

$178(68.7)$

95

83

(Continued) 


\begin{tabular}{lcccc}
\hline Characteristic & Overall(\%) & LMR $<\mathbf{5 . 2}$ & LMR $\geq \mathbf{5 . 2}$ & P-value \\
\hline $\begin{array}{l}\text { Chemotherapy } \\
\text { CEF }\end{array}$ & $82(31.7)$ & 41 & 41 & $0.229^{\mathrm{a}}$ \\
$\quad$ TAC & $177(68.3)$ & 103 & 74 & \\
$\begin{array}{l}\text { Lymphocyte } \\
\text { count }\left(\mathbf{1 0}^{9} / \mathbf{L}\right)\end{array}$ & $1.76(0.4-5.3)^{*}$ & $1.59(0.4-4)^{*}$ & $1.98(0.9-5.3)^{*}$ & $0.000^{\mathrm{b}}$ \\
$\begin{array}{l}\text { Monocyte } \\
\text { count }\left(\mathbf{1 0}^{\boldsymbol{9}} / \mathbf{L}\right)\end{array}$ & $0.41(0.1-2.2)^{*}$ & $0.51(0.2-2.2)^{*}$ & $0.28(0.1-0.5)^{*}$ & $0.000^{\mathrm{b}}$ \\
\hline
\end{tabular}

*Representing mean and range in the bracket; the mean LMR level was 5.4 (range, 0.3-27.7).

LMR, lymphocyte-to-monocyte ratio; ER, estrogen receptor; PR, progesterone receptor; HER2, human epithelial receptor 2.

${ }^{a}$ Chi-square test by two-sided Pearson's exact test.

${ }^{b}$ Wilcoxon rank-sum test.
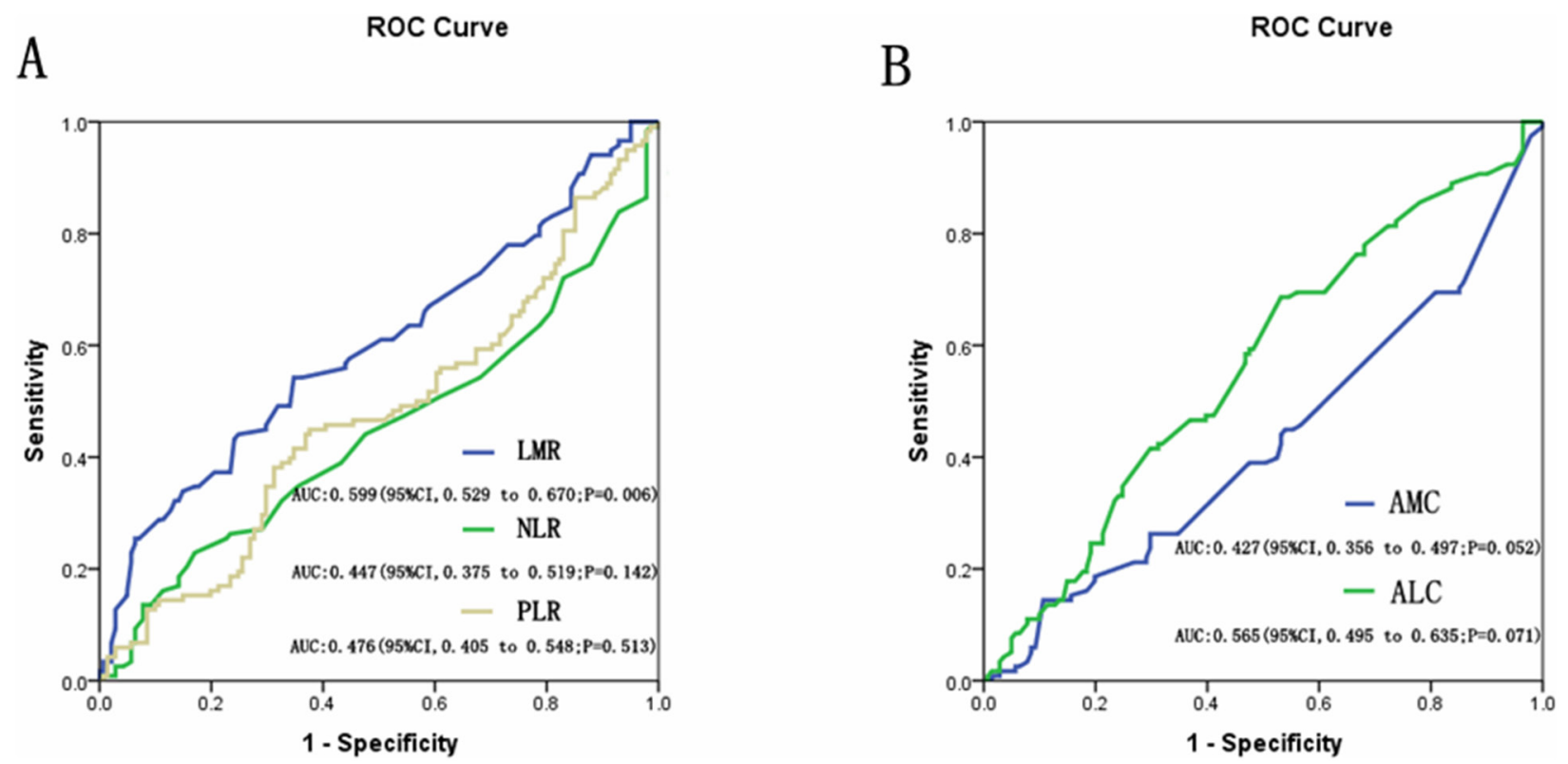

Figure 1: A. Receiver operating characteristics curves (ROC) and area under the curve (AUC) for LMR, NLR, and PLR in the study; B. Receiver operating characteristics curves (ROC) and area under the curve (AUC) for AMC and ALC in the study.

In this study, we demonstrated that a LMR value of 5.2 was the optimal cutoff to predict DFS in luminal breast cancer patients. To the best of our knowledge, this is the first study to investigate an appropriate LMR cutoff value for luminal breast cancer. The tumor-infiltrating immune cells are highly heterogeneous between the different breast cancer subtypes [35-38]. As a result of this heterogeneity, the different breast cancer subtypes will induce different host immune responses, which will give rise to various LMR ratios depending on the breast cancer subtype. Consequently, this subtype-dependent LMR ratio may be responsible for the controversy surrounding the prognostic value of the LMR investigated by previous studies. Therefore, it is necessary to define a cut-off value for the LMR applied exclusively to the specific breast cancer subtypes, such as luminal breast cancer.

In addition, we found that the DFS was better in patients with a $L M R \geq 5.2$ that received a CEF regimen, as compared with those receiving a TAC regimen. As we know, the distinguished difference between the CEF and the TAC regimen is 5-FU. In our study, we also found that 5-FU induced FAS expression in luminal breast cancer cells MCF-7 and T47D suggested that 5-FU could trigger tumor cell death through Fas/FasL dependent 


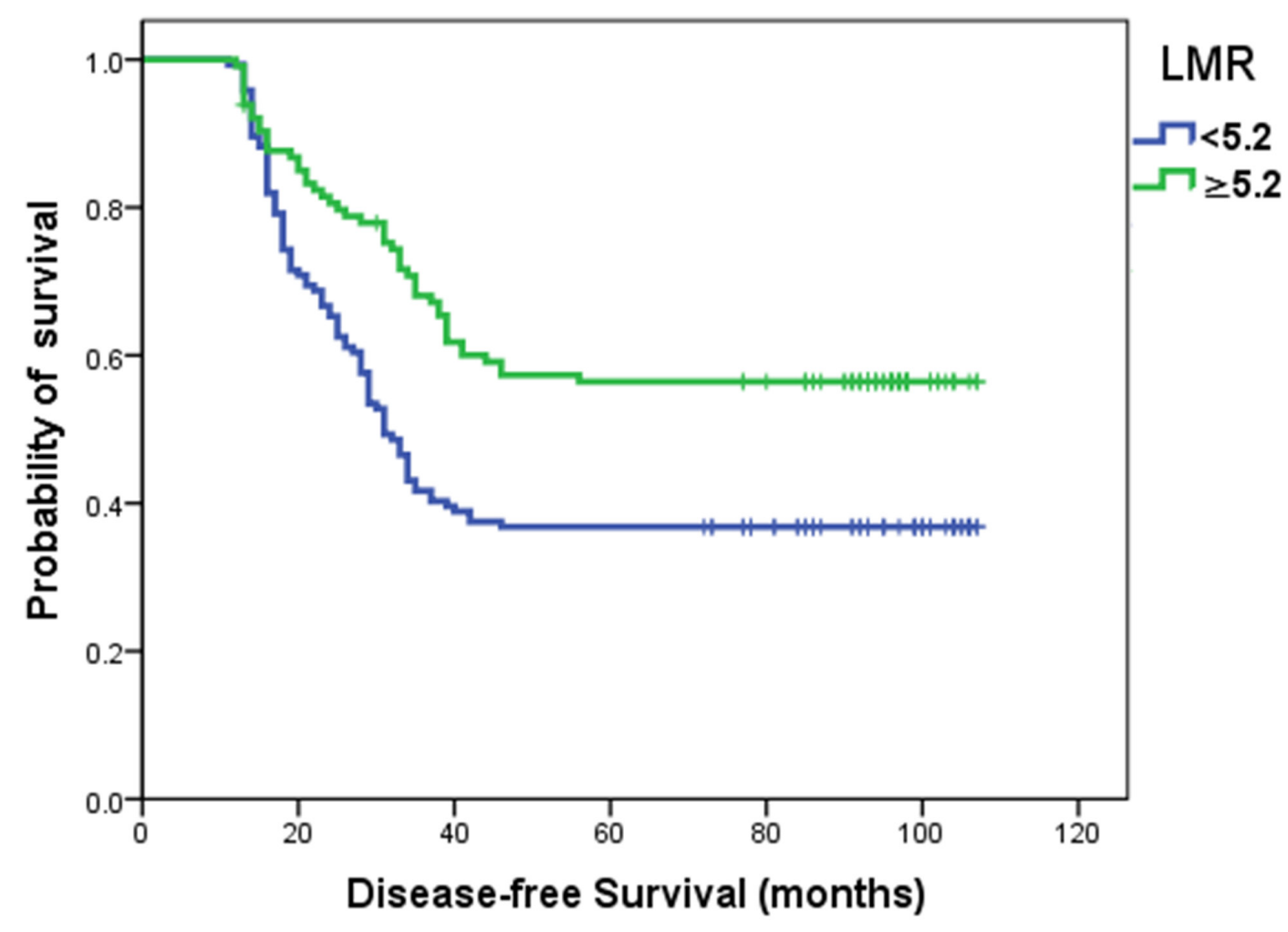

Figure 2: Kaplan-Meier curves for DFS according to optimal cutoff points of LMR.

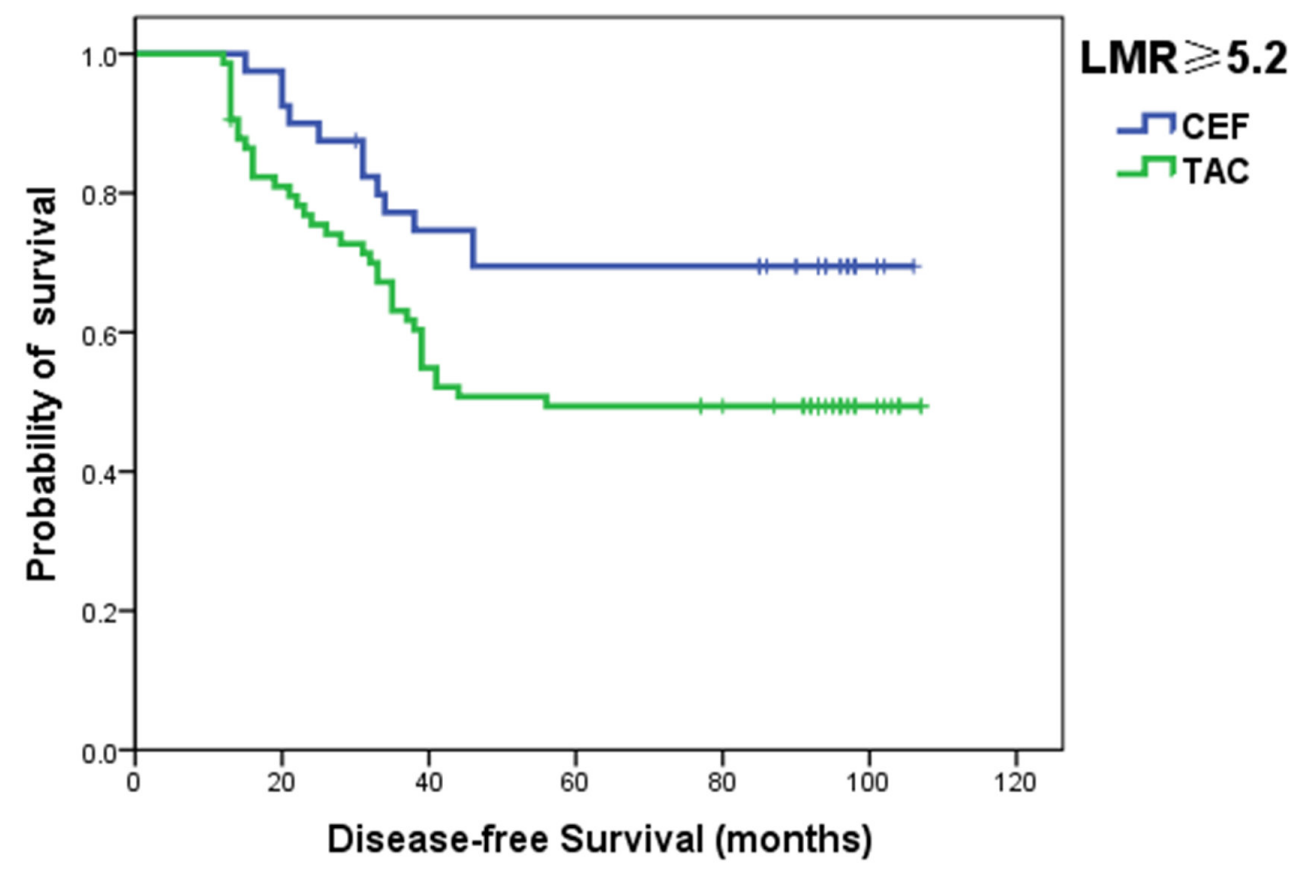

Figure 3: Kaplan-Meier curves for DFS in luminal patients with a LMR $\geq 5.2$ according to the chemotherapy regimen. 
Table 2: Univariate and multivariate analyses of clinicopathologic characteristics for DFS in luminal breast cancer

\begin{tabular}{|c|c|c|c|c|}
\hline \multirow[b]{2}{*}{ Variable } & \multicolumn{2}{|c|}{ Univariate analysis } & \multicolumn{2}{|c|}{ Multivariate analysis } \\
\hline & HR(95\% CI) & P-value & $\operatorname{HR}(95 \% \mathrm{CI})$ & P-value \\
\hline $\operatorname{LMR}(<5.2 ; \geq 5.2)$ & $0.560(0.395-0.793)$ & 0.001 & $0.582(0.408-0.831)$ & 0.003 \\
\hline Lymph node status & $1.748(1.167-2.620)$ & 0.007 & $1.560(0.986-2.468)$ & 0.057 \\
\hline Chemotherapy & $1.676(1.143-2.458)$ & 0.008 & $1.527(1.014-2.301)$ & 0.043 \\
\hline Menopause status & $0.827(0.594-1.153)$ & 0.262 & $0.815(0.500-1.327)$ & 0.410 \\
\hline Age & $1.158(0.830-1.614)$ & 0.389 & $1.118(0.683-1.830)$ & 0.658 \\
\hline Tumor size & $0.982(0.653-1.478)$ & 0.931 & $0.852(0.556-1.305)$ & 0.460 \\
\hline $\begin{array}{l}\text { Histological grade } \\
\text { status }\end{array}$ & $0.996(0.635-1.560)$ & 0.985 & $0.889(0.540-1.464)$ & 0.645 \\
\hline Ki 67 status & $1.055(0.757-1.469)$ & 0.753 & $1.108(0.789-1.556)$ & 0.552 \\
\hline
\end{tabular}

Bold values are significant $(\mathrm{P}<0.05)$. DFS, disease-free survival; LMR, lymphocyte-to-monocyte ratio; HR, hazard ratio
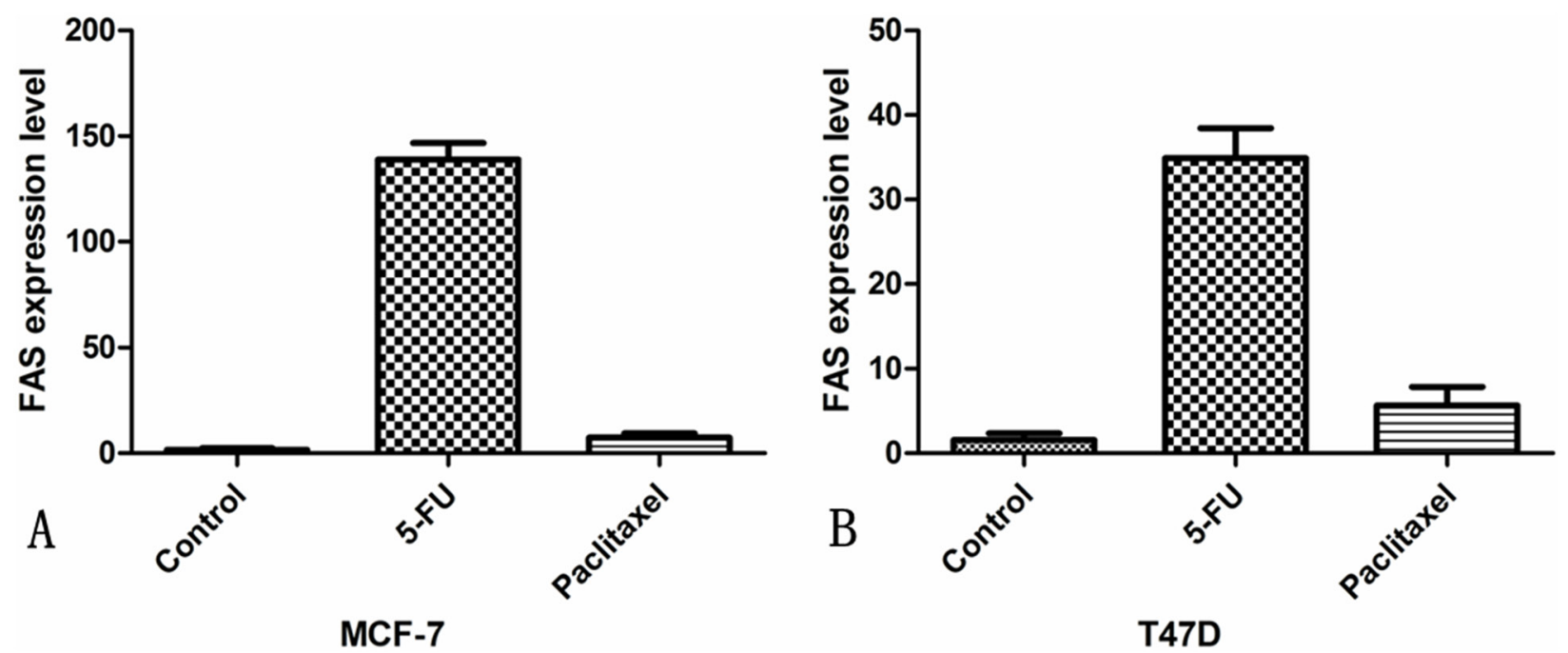

Figure 4: FAS expression level in breast cancer cell lines. A. MCF-7 breast cancer cells; B. T47D breast cancer cells.

T-cell-mediated eradication. Hence, the improved effect of 5-FU was associated with higher levels of the LMR. Increasing evidence has demonstrated that 5-FU exhibits antitumor immunomodulatory activity by triggering host immune response and eliminating tumor cells, which is known as chemotherapy-induced immunogenic cell death (ICD). Specifically, 5-FU-induced ICD exerts its chemoimmunotherapeutic effects by recruiting innate or adaptive immune cells, enhancing cancer cell antigenicity, and releasing cytokine secretion [39-42]. The prerequisite to achieve ICD efficacy is a favorable immune system in patients, which means that the surrogate marker of host immune response, the LMR, needs to remain at an elevated level, and our results provided evidence to support this assumption.

In conclusion, our study identified an optimal cut-off for the LMR restricted to luminal subtype breast cancer. Using this LMR index, our results revealed that an elevated LMR could be regarded as an independent prognostic factor in luminal breast cancer patients. Moreover, our results indicated that the elevated LMR level enhanced the 5-FU sensitivity in luminal breast cancer patients. Therefore, the combination of lymphocyte-monocyte ratio and chemotherapy may be a promising strategy for 
anticancer treatments. As this was a retrospective and single-center study, further investigations need to be performed to validate our conclusion.

\section{MATERIALS AND METHODS}

\section{Patients}

This study, including the procedures for patient enrollment and recruitment, was approved by the Institutional Review Board of Tumor Hospital of Harbin Medical University and informed consent was obtained from each participant. The breast cancer patients were recruited between January 1st, 2006, and December 30th, 2008. The inclusion criteria were no metastatic lesions before surgery, infiltrating ductal carcinoma, ER/PR positive, and complete clinical and pathologic data. All patients in this study underwent an adjuvant chemotherapy regimen consisting of CEF (cyclophosphamide 600 $\mathrm{mg} / \mathrm{m}^{2}$, day 1 ; epirubicin $60 \mathrm{mg} / \mathrm{m}^{2}$, day 1 ; and $5-\mathrm{FU}$ $600 \mathrm{mg} / \mathrm{m}^{2}$, day 1 ; every 21 days for 6 cycles) or TAC (paclitaxel $175 \mathrm{mg} / \mathrm{m}^{2}$, day 1; doxorubicin $50 \mathrm{mg} / \mathrm{m}^{2}$, day 1; cyclophosphamide $500 \mathrm{mg} / \mathrm{m}^{2}$, day 1; every 21 days for six cycles). Depending on the lymph node and HER2 status of the breast cancer, patients were selectively given radiation and targeted therapy. Patients with positive ER or PR status received endocrine therapy (20 mg of tamoxifen per day) for 5 years. After surgery, every patient was followed up regularly until December 2014 or until death. Patients who developed disease relapse were confirmed by adequate diagnostic imaging modalities and pathology during the follow-ups.

\section{Methods}

\section{Blood sample analysis}

The peripheral blood was collected in tubes containing ethylenediaminetetraacetic acid. The peripheral blood cells were counted by Sysmex XT-1800 Automated Hematology System (Shanghai, China). The peripheral LMR was calculated as the ratio of absolute counts between lymphocytes and monocytes. The peripheral NLR was translated as the ratio of absolute counts between neutrophils and lymphocytes. The peripheral PLR was interpreted as the ratio of absolute counts between platelets and lymphocytes. The peripheral blood samples were obtained after breast cancer diagnosis and before any treatment. All of the enrolled patients had no hematologic disorders or acute infections, implying that the cell counts could demonstrate the normal baseline value.

\section{Immunohistochemistry}

All breast cancer tissues were formalin fixed and paraffin embedded. The immunohistochemical analysis was executed as described previously [20]. In brief, slides were incubated with an HER2 polyclonal antibody (Dako, CA, USA), P53 (1:500, DO-7; Dako), or Ki-67 (1:300, MIB-1; Dako). The stained tissues were evaluated according to the densities of staining and the number of stained cells. The samples were regarded as hormone receptor positive if cancer cells expressed an ER and/or PR greater than or equal to $10 \%$. Tissues were considered positive for Ki-67 when more than $20 \%$ of the cells examined were stained. For P53, any staining of cells was deemed as P53 positive. The HER2 status was been evaluated according to the 2013 ASCO/CAP recommendations [21]. Each section was scanned at $\times 100$ and $\times 400$ magnification by microscope (Olympus BX51). Immunohistochemical (IHC)-based subtyping was determined according to the following definitions adopted by the 2011 St Gallen Consensus Panel: IHC-luminal (ER/ $\mathrm{PR}+)$; IHC-luminal A (ER/PR+, HER2-, and Ki-67 index $<14 \%$ ); IHC-luminal B (ER/PR+, HER2-, and Ki67 index $\geq 14 \%$ or ER/PR+, HER2+) [3]. The other subtypes were not included in the study.

\section{Cell culture and treatment}

MCF-7 and T47D cells were grown in in Roswell Park Memorial 1640 medium (RPMI 1640; SigmaAldrich; MO, USA) containing 10\% fetal calf serum, $100 \mathrm{mg} / \mathrm{ml}$ streptomycin and $100 \mathrm{units} / \mathrm{ml}$ penicillin and incubated at $37^{\circ} \mathrm{C}$ supplemented with $5 \%$ of $\mathrm{CO}^{2}$. The cells were subcultured on 6-well plates for further experiments. After a $24 \mathrm{~h}$ incubation to allow cell attachment, paclitaxel $(0.2 \mu \mathrm{M})$ or $5-\mathrm{FU}(20 \mu \mathrm{g} / \mathrm{ml})$ were added to cells for $6 \mathrm{~h}$.

\section{Real-time PCR}

Total RNA was extracted with the TRIzol reagent and cDNA was synthesized using a Prime-Script RT reagent kit (Takara Bio, Inc. Otsu, Shiga, Japan). The following PCR conditions were used: 1 cycle at $95^{\circ} \mathrm{C}$ for $10 \mathrm{~min}$ and then 40 cycles of $15 \mathrm{~s}$ at $95^{\circ} \mathrm{C}$ and 1 min at $60^{\circ} \mathrm{C}$. Real-time PCR was performed on the ABI PRISM7500 Real-Time PCR System (Applied Biosystems) according to the manufacturer's instructions. The expression changes of the RNA was normalized to $\beta$-actin RNA. The sequences of PCR primers used were as follows: sense, 5'-GTGAGGGAAGCGGTTTACGA3 'and anti-sense, 5' - AGATGCCCAGCATGGTTGTT-3' for Fas; sense, 5'-CCACGAAACTACCTTCAACTCC-3' and anti-sense, 5'-GTGATCTCCTTCTGCATCCTGT-3' for $\beta$-actin.

\section{Statistical methods}

DFS was calculated as the time between diagnosis and disease relapse, or death from breast cancer. To evaluate whether increased LMR, NLR, PLR, AMC, or 
ALC correlated with prognosis of patients with breast cancer, we chose patients with disease relapse or cancerrelated death during the follow-ups and defined them as the poor prognosis group. Other patients were included in the good prognosis group. ROC curves, and AUC, were performed to further evaluate the prediction status of LMR, NLR, PLR, AMC, and ALC. Sensitivity and specificity were calculated by the optimal cutoff points on the ROC curves, which decided the maximum value (sensitivity + specificity -1$)$ of the Youden index [22].

The Chi-square or Fisher's exact tests were used for comparing clinicopathologic features between different LMR groups. Continuous variables, reported as lymphocyte and monocyte counts, were compared by the Wilcoxon rank-sum test. Risk factors of DFS were analyzed by univariate analysis with the log-rank test and multivariate analysis with the Cox proportional hazard model. The survival curves were performed by the Kaplan-Meier method and the comparisons between groups were assessed by the log-rank test. The results were showed as hazard ratios HRs and 95\% CIs. The significance of the relative differential expression of FAS was determined by the two-tailed unpaired test. Statistical significance was decided as $P$-values $<0.05$. All statistical analyses were performed using the IBM SPSS 20.0 software (IBM, USA).

\section{CONFLICTS OF INTEREST}

The authors declare no competing interests.

\section{GRANT SUPPORT}

This study was supported by the National Natural Science Foundation of China (Grant No. 81372839) and innovation fund of Harbin Medical University (Grant No.YJSCX2015-64HYD).

\section{REFERENCES}

1. Lahart IM, Metsios GS, Nevill AM, Carmichael AR. Physical activity, risk of death and recurrence in breast cancer survivors: A systematic review and meta-analysis of epidemiological studies. Acta Oncol. 2015; 54: 635-654.

2. Prat A, Parker JS, Karginova O, Fan C, Livasy C, Herschkowitz JI, He X, Perou CM. Phenotypic and molecular characterization of the claudin-low intrinsic subtype of breast cancer. Breast Cancer Res. 2010; 12:R68.

3. Prat A, Cheang MC, Martín M, Parker JS, Carrasco E, Caballero R, Tyldesley S, Gelmon K, Bernard PS, Nielsen TO, Perou CM. Prognostic significance of progesterone receptor-positive tumor cells within immunohistochemically defined luminal A breast cancer. J Clin Oncol. 2013; 31:203-209.
4. Almstedt K, Schmidt M. Targeted therapies overcoming endocrine resistance in hormone receptor-positive breast cancer. Breast Care (Basel). 2015; 10:168-172.

5. Huovinen R, Auvinen P, Mattson J, Joensuu H. Adjuvant drug therapies for breast cancer. Duodecim. 2015; 131:23-28.

6. Couzin-Frankel J. Breakthrough of the year 2013. Cancer immunotherapy. Science. 2013; 342:1432-1433.

7. Vacchelli E, Aranda F, Eggermont A, Galon J, SautèsFridman C, Cremer I, Zitvogel L, Kroemer G, Galluzzi L. Trial Watch: Chemotherapy with immunogenic cell death inducers. Oncoimmunology. 2014; 3:e27878.

8. Grivennikov SI, Greten FR, Karin M. Immunity, inflammation, and cancer. Cell. 2010; 140:883-899.

9. Stromnes IM, Greenberg PD, Hingorani SR. Molecular pathways: myeloid complicity in cancer. Clin Cancer Res. 2014; 20:5157-5170.

10. Bane A, Viloria-Petit A, Pinnaduwage D, Mulligan AM, O'Malley FP, Andrulis IL. Clinical-pathologic significance of cancer stem cell marker expression in familial breast cancers. Breast Cancer Res Treat. 2013; 140:195-205.

11. Jiang L, Jiang S, Situ D, Lin Y, Yang H, Li Y, Long H, Zhou Z. Prognostic value of monocyte and neutrophils to lymphocytes ratio in patients with metastatic soft tissue sarcoma. Oncotarget. 2015; 6:9542-9550. doi: 10.18632/ oncotarget.3283.

12. el Aziz LM. Blood neutrophil-lymphocyte ratio predicts survival in locally advanced cancer stomach treated with neoadjuvant chemotherapy FOLFOX 4. Med Oncol. 2014; $31: 311$.

13. Neofytou K, Smyth EC, Giakoustidis A, Khan AZ, Cunningham D, Mudan S. Elevated platelet to lymphocyte ratio predicts poor prognosis after hepatectomy for liveronly colorectal metastases, and it is superior to neutrophil to lymphocyte ratio as an adverse prognostic factor. Med Oncol. 2014; 31:239.

14. Jiang L, Zhao Z, Jiang S, Lin Y, Yang H, Xie Z, Lin Y, Long $\mathrm{H}$. Immunological markers predict the prognosis of patients with squamous non-small cell lung cancer. Immunol Res. 2015; 62:316-324.

15. Porrata LF, Inwards DJ, Ansell SM, Micallef IN, Johnston PB, Hogan WJ, Markovic SN. Infused autograft lymphocyte to monocyte ratio and survival in diffuse large B cell lymphoma. Biol Blood Marrow Transplant. 2014; 20:1804-1812.

16. Luo G, Guo M, Liu Z, Xiao Z, Jin K, Long J, Liu L, Liu C, Xu J, Ni Q, Yu X. Blood neutrophil-lymphocyte ratio predicts survival in patients with advanced pancreatic cancer treated with chemotherapy. Ann Surg Oncol. 2015; 22:670-676.

17. Ni XJ, Zhang XL, Ou-Yang QW, Qian GW, Wang L, Chen S, Jiang YZ, Zuo WJ, Wu J, Hu X, Shao ZM. An elevated peripheral blood lymphocyte-to-monocyte ratio predicts favorable response and prognosis in locally advanced breast 
cancer following neoadjuvant chemotherapy. PLoS One. 2014; 9:e111886.

18. Azab B, Shah N, Radbel J, Tan P, Bhatt V, Vonfrolio S, Habeshy A, Picon A, Bloom S. Pretreatment neutrophil/ lymphocyte ratio is superior to platelet/lymphocyte ratio as a predictor of long-term mortality in breast cancer patients. Med Oncol. 2013; 30:432.

19. Cihan YB, Arslan A, Cetindag MF, Mutlu H. Lack of prognostic value of blood parameters in patients receiving adjuvant radiotherapy for breast cancer. Asian Pac J Cancer Prev. 2014;15:4225-4231.

20. Teng MW, Ngiow SF, Ribas A, Smyth MJ. Classifying Cancers Based on T-cell Infiltration and PD-L1. Cancer Res. Cancer Res. 2015; 75:2139-2145.

21. Wolff AC, Hammond ME, Hicks DG, Dowsett M, McShane LM, Allison KH, Allred DC, Bartlett JM, Bilous M, Fitzgibbons P, Hanna W, Jenkins RB, Mangu PB, et al. Recommendations for human epidermal growth factor receptor 2 testing in breast cancer: American Society of Clinical Oncology/College of American Pathologists clinical practice guideline update. J Clin Oncol. 2013; 31:3997-4013.

22. Youden WJ. Index for rating diagnostic tests. Cancer. 1950; 3:32-35.

23. Apetoh L, Ladoire S, Coukos G, Ghiringhelli F. Combining immunotherapy and anticancer agents: the right path to achieve cancer cure? Ann Oncol. 2015; 26:1813-1823.

24. Domagala-Kulawik J. The role of the immune system in non-small cell lung carcinoma and potential for therapeutic intervention. Transl Lung Cancer Res. 2015; 4:177-190.

25. Chang Y, An H, Xu L, Zhu Y, Yang Y, Lin Z, Xu J. Systemic inflammation score predicts postoperative prognosis of patients with clear-cell renal cell carcinoma. Br J Cancer. 2015; 113:626-633.

26. García-Martínez E, Gil GL, Benito AC, GonzálezBillalabeitia E, Conesa MA, García García T, GarcíaGarre E, Vicente V, Ayala de la Peña F. Tumor-infiltrating immune cell profiles and their change after neoadjuvant chemotherapy predict response and prognosis of breast cancer. Breast Cancer Res. 2014; 16:488.

27. Noy R, Pollard JW. Tumor-associated macrophages: from mechanisms to therapy. Immunity. 2014; 41:49-61.

28. Qian BZ, Pollard JW. Macrophage diversity enhances tumor progression and metastasis. Cell. 2010; 141:39-51.

29. Wei X, Huang F, Wei Y, Jing H, Xie M, Hao X, Feng R. Low lymphocyte-to-monocyte ratio predicts unfavorable prognosisin non-germinal center type diffuse large B-cell lymphoma. Leuk Res. 2014; 38:694-698.

30. Temraz S, Mukherji D, Farhat ZA, Nasr R, Charafeddine M, Shahait M, Wehbe MR, Ghaida RA, Gheida IA, Shamseddine A. Preoperative lymphocyte-to-monocyte ratio predicts clinical outcome in patients undergoing radical cystectomy for transitional cell carcinoma of the bladder: a retrospective analysis. BMC Urol. 2014; 14:76.
31. Tang X. Tumor-associated macrophages as potential diagnostic and prognostic biomarkers in breast cancer. Cancer Lett. 2013; 332:3-10.

32. Wynn TA, Chawla A, Pollard JW. Macrophage biology in development, homeostasis and disease. Nature. 2013; 496:445-455.

33. West NR, Milne K, Truong PT, Macpherson N, Nelson $\mathrm{BH}$, Watson PH. Tumor-infiltrating lymphocytes predict response to anthracycline-based chemotherapy in estrogen receptor-negative breast cancer. Breast Cancer Res. 2011; 13:R126.

34. Seo AN, Lee HJ, Kim EJ, Kim HJ, Jang MH, Lee HE, Kim YJ, Kim JH, Park SY. Tumour-infiltrating CD8+ lymphocytes as an independent predictive factor for pathological complete response to primary systemic therapy in breast cancer. Br J Cancer. 2013; 109:2705-2713.

35. Bianchini G, Qi Y, Alvarez RH, Iwamoto T, Coutant C, Ibrahim NK, Valero V, Cristofanilli M, Green MC, Radvanyi L, Hatzis C, Hortobagyi GN, Andre F, Gianni L, Symmans WF, Pusztai L. Molecular anatomy of breast cancer stroma and its prognostic value in estrogen receptor-positive and -negative cancers. J Clin Oncol. 2010; 28:4316-4323.

36. Sabatier R, Finetti P, Cervera N, Lambaudie E, Esterni B, Mamessier E, Tallet A, Chabannon C, Extra JM, Jacquemier J, Viens P, Birnbaum D, Bertucci F. A gene expression signature identifies two prognostic subgroups of basal breast cancer. Breast Cancer Res Treat. 2011; 126:407-420.

37. Kimbung S, Kovács A, Danielsson A, Bendahl PO, Lövgren K, Frostvik Stolt M, Tobin NP, Lindström L, Bergh J, Einbeigi Z, Fernö M, Hatschek T, Hedenfalk I Contrasting breast cancer molecular subtypes across serial tumor progression stages: biological and prognostic implications. Oncotarget. 2015; 6:33306-33318. doi: 10.18632/oncotarget.5089.

38. Rathore AS, Kumar S, Konwar R, Makker A, Negi MP, Goel MM. CD3+, CD4+ \& CD8+ tumour infiltrating lymphocytes (TILs) are predictors of favourable survival outcome in infiltrating ductal carcinoma of breast. Indian J Med Res. 2014; 140:361-369.

39. Cottone L, Capobianco A, Gualteroni C, Perrotta C, Bianchi ME, Rovere-Querini P, Manfredi AA. 5-Fluorouracil causes leukocytes attraction in the peritoneal cavity by activating autophagy and HMGB1 release in colon carcinoma cells. Int J Cancer. 2015; 136:1381-1389.

40. Ghiringhelli F, Bruchard M, Apetoh L. Immune effects of 5-fluorouracil: Ambivalence matters. Oncoimmunology. 2013; 2:e23139.

41. Ghiringhelli F, Apetoh L. Enhancing the Anticancer Effects of 5-Fluorouracil: Current Challenges and Future Perspectives. Biomed J. 2015; 38:111-116.

42. Apetoh L, Ladoire S, Coukos G, Ghiringhelli F. Combining immunotherapy and anticancer agents: the right path to achieve cancer cure? Ann Oncol. 2015; 26:1813-1823. 